
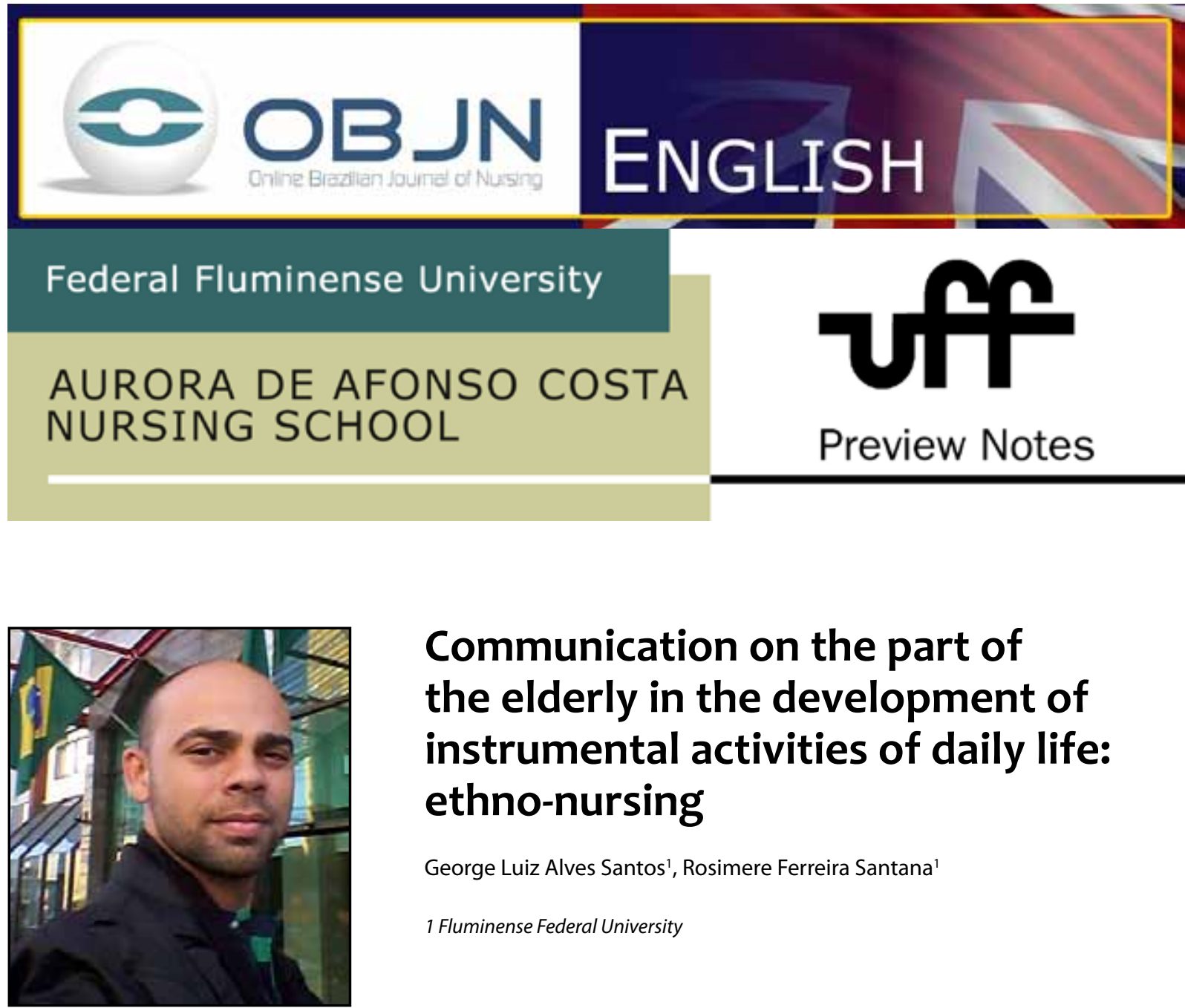

\title{
Communication on the part of the elderly in the development of instrumental activities of daily life: ethno-nursing
}

George Luiz Alves Santos ${ }^{1}$, Rosimere Ferreira Santana ${ }^{1}$

1 Fluminense Federal University

\begin{abstract}
Aim: To understand the communication established by the elderly who attend groups for seniors in the development of Instrumental Activities of Daily Living (IADL). Method: This is a qualitative, descriptive and ethnographic study. The setting will be an extension project for seniors at a public university in Niterói (RJ), Brazil. We involved the elderly as key informants, and the practitioners who work directly with them were likewise involved as general informants. For the production of data the following were used: (I) observation without participation; (II) observation with limited participation; (III) participation with continuous observation and (IV) reflection and reconfirmation of results. For data analysis the following were utilized: (I) description and documentation of raw data; (II) identification and categorization of descriptors and components; (III) standard and textual analysis and (IV) major issues, research results, theoretical formulations and recommendations. Expected results: To establish an intervention plan with regard to methods for improving communication for IADL that may promote the autonomy and independence of seniors.
\end{abstract}

Descriptors: Communication; Elderly; Geriatrics; Geriatric Nursing. 


\section{INTRODUCTION}

Communication permeates human relationships. Interaction, including its central purpose, presents itself in various forms which could be written and verbal or non-verbal ${ }^{(1)}$, in addition to pervading the individual, family and collective dimensions ${ }^{(2)}$.

However, the hallmark of modern society is an environment featuring rapid and constant change. Communication itself has nowadays become fast, dynamic and focused on technology. Opposed to the described sociocultural context above are the elderly: they feature distinct communicational habits ${ }^{(1)}$ which may lead to social exclusion.

The Instrumental Activities of Daily Living (IADL) are complex actions that require adaptation, autonomy and social interaction on the part of seniors for their implementation. In everyday life, goods and services may not be adapted to their needs, as occurs, for example, with the use of the telephone, in public transportation, in purchases, and in financial transfers and money use.

Seniors groups may be highlighted as a place for social (re)integration of the elderly, in which it is possible to question the reality of the problems in communication that exist for the performance of IADL. Thus, from this study, we intend to contribute to nursing interventions by encouraging communication as a means of maintaining the autonomy and independence of older people.

\section{GUIDING QUESTION}

What is the form of communication for seniors who attend groups for seniors in the development of IADL?

\section{GENERAL OBJECTIVE}

To understand the communication processes established by the elderly who attend groups for seniors in the development of IADL.

\section{SPECIFIC AIMS}

To describe the communication processes of elders who attend groups for seniors in the development of IADL;

To analyze the constituent elements that are facilitators or act as noise/barriers in the communication of elderly people for the development of these activities;

To discuss the implications of communication among the elderly who attend groups for seniors in the development of IADL in the Gerontological Nursing care.

\section{THEORETICAL REFERENCES}

The communication process ${ }^{(1)}$ was adopted as a theoretical reference, structured by source, message, channel and receiver. And, as a theoretical and methodological framework, the theory of diversity and universality of cultural care $^{(3)}$ was adopted, including the rising sun model, which consists of the following factors: technological, political, legal, economic, educational, religious, philosophical, familial, social, cultural, beliefs and lifestyle.

\section{METHOD}

This is a qualitative and descriptive study, outlined in ethno-nursing. As a technique for data collection, field diaries and semi-structured interviews, including questions regarding 
socio-demographic characterization, problems and research objectives, based on a theoretical framework, will be used.

For data production, we will use the observation-participation-reflection model ${ }^{(3)}$ composed of the following stages: (I) observation and action involving active listening (without active participation); (II) observation with limited participation; (III) participation with continuous observation; and (IV) reflection and reconfirmation of the results in conjunction with the informants.

The data analysis steps will be as follows: (i) the collection, description and documentation of raw data; (II) the identification and categorization of descriptors and components; (III) standard and textual analysis; and (IV) a consideration of the major themes, research results, theoretical formulations and recommendations.

The research setting is an extension project of the School of Social Services of a public university situated in the city of Niterói, Rio de Janeiro, Brazil. The data collection period is from July to October 2014.

The research subjects will be divided into key informants and general informants. By adopting the criterion of data saturation, a minimum sample size was established. The key informants will be 30 seniors who attend seniors groups, including independent and autonomous subjects. They will perform the IADL regularly as part of the activities of the extension project and depending on their availability for scheduling meetings in advance. Participants, who discontinue activities as part of the project extension, who do not answer the telephone, or who do not show up for the interview and observations on the scheduled day, will be excluded.

The general informants are six subjects who developed activities as part of the exten- sion project with elderly people, six subjects from commercial institutions and six public transport representatives. Those who have been involved in direct and regular activities with senior citizens for at least one year will be included, as well as those individuals working as tellers or cashiers for the elderly at commercial institutions. Those who miss the interview on the scheduled day will be excluded, in addition to incomplete interviews.

The present study is part of the project entitled "Communication between elderly-elderly family and society: implications for nursing care", approved by the hosting institution and by the local Research Ethics Committee, under opinion number 246 268, on 10 May 2013. The ethical and legal aspects, recommended by Resolution $466 / 12$ on human research, were respected.

\section{REFERENCES}

1. Berlo DK. O Processo de comunicação: introdução à teoria e à prática. 9 ed. São Paulo: Martins Fontes; 1999.

2. Oliveira TR, Simões SMF. Communication faces in the practice of nursing. A bibliographic research. Online Braz J Nurs [Internet]. 2010[cited 2014 Abr. 20] 9(2). Available from: http://www.objnuhttp://www.objnursing.uff.br/index.php/nursing/ article/view/j.16764285.2010.3116/698rsing. uff.br/index.php/nursing/article/ view/j.1676-4285.2010.3116/698

\footnotetext{
Marilyn RM, Sandra JM, Hiba W, Renee B. Ethnonursing: a qualitative research method for studying culturally competent care across disciplines. International Journal of Qualitative Methods [Internet] 2012 [cited 2014 Jun 06]; 11(3). Available from: https://ejournals.library.ualberta.ca/ index.php/IJQM/article/view/8986/14130
} 
All authors participated in the phases of this publication in one or more of the following steps, in According to the recommendations of the International Committee of Medical Journal Editors (ICMJE, 2013): (a) substantial involvement in the planning or preparation of the manuscript or in the collection, analysis or interpretation of data; (b) preparation of the manuscript or conducting critical revision of intellectual content; (c) approval of the versión submitted of this manuscript. All authors declare for the appropriate purposes that the responsibilities related to all aspects of the manuscript submitted to OBJN are yours. They ensure that issues related to the accuracy or integrity of any part of the article were properly investigated and resolved. Therefore, they exempt the OBJN of any participation whatsoever in any imbroglios concerning the content under consideration. All authors declare that they have no conflict of interest of financial or personal nature concerning this manuscript which may influence the writing and/or interpretation of the findings. This statement has been digitally signed by all authors as recommended by the ICMJE, whose model is available in http://www. objnursing.uff.br/normas/DUDE_eng_13-06-2013.pdf

Received: 06/15/2014

Revised: 08/04/2014

Approved: 08/04/2014 